Sir: I was aghast to discover my wife's impertinent letter in your excellent and informative correspondence column. (Psychiatric Bulletin, March 1994, 18, 175). I regret to say that the letter was sent without my prior knowledge or indeed my consent. I have now rebuked her and have sternly forbidden further illicit selfindulgences of that nature. Kindly regard the correspondence as now closed and please accept my apologies for any inconvenience incurred.

A.D. MACDONALD, Hutt Valley Health Corporation Ltd., 32 Pretorla Street, Lower Hutt, New Zealand

\section{Day care in old age psychiatry}

Sir: I write to join the debate between Dr Ball (Psychiatric Bulletin, 1993; 17, 427-428) and Drs Bergmann \& Levy (Psychiatric Bulletin, January 1994, 18, 53-54).

Sadly, Dr Ball is correct in his assertions; that the various models of service delivery have not been tested with each other or even against their own aspirations. Perhaps we may learn from our geriatric colleagues.

Geriatric day hospitals have been assessed for efficiency and effectiveness (Zeeli \& Isaacs, 1988) when it was found that; only one third of medically specified objectives were attained; only one third of patients felt that they had improved, and only one third of carers had experienced any relief from strain.

More worrying is Eagle et al's (1987) review of the four randomised control studies undertaken of gerlatric day care. In only one of these studies was any credible improvement shown in either physical or emotional function in the day hospital group. Moreover, in all studies substantially greater costs were incurred by the day hospital group compared with other forms of therapy. mainly augmented community care.

These findings should come as no surprise to Dr Bergmann as his own research (Bergmann et al, 1978) showed that elderly dements living on their own falled to survive in the community however intensive the community support provided, including intensive day hospital attendance.

The effectiveness and efficiency of psychogeriatric day hospitals remains in question. What is worrisome about his correspondence is the implicit criticism by Drs Bergmann \& Levy that Dr Ball should not raise the question. Perhaps it is well that Dr Ball reminds us of the need for this work to be undertaken. The same question will be asked by health economists, purchasers and rival providers in other settings, such as the negotiation of future contracts. We may then find that other providers, such as the voluntary and private sectors, are able to provide answers we cannot.
Bergmann, K., Foster, E.M., Justice, A.W. \& Matthews, V. (1978). Management of the demented elderly in the community. British Journal of Psychiatry. 132, 441-449.

Eagle, D.A., Guyatt, G.. Patterson, C. \& Turpie. I. (1987). Day hospitals' cost and effectiveness. A summary. Gerontologist. 27, 735-740.

ZEELI, D. \& ISAACS. B. (1988). The efficiency and effectiveness of geriatric day hospitals. Postgraduate Medical Journal. 64, 683-686.

R.M. PHILPOT, EMI Directorate, Sir Douglas Crawford Unit, Mossley Hill Hospital, Liverpool L18 8BV

Sir: When a debate goes on simultaneously in two journals it is difficult for those not central to it to follow the arguments. If Dr Philpott consults the survey of day hospital provision for elderly mentally ill directed by one of us (Beats et al, 1993) and quoted in our letter, he will read: "Day hospitals for the elderly mentally ill seem to have grown despite the paucity of research evidence of their efficacy ... . work is urgently needed while diametrically opposed views about the need for NHS day hospitals are held by influential clinicians in the field". This may reassure him that far from implicitly or explicitly criticising anyone for raising these questions, we have done so ourselves. What we are saying is that until hard evidence about old age psychiatry day hospitals becomes available (geriatric care is quite different) it would be unwise to adopt entrenched positions or to dismantle services painfully and empirically built up over many years. Indeed, the results of the temporary closure of an old age psychiatry day hospital are described by Dr C. Ball (Rolleston \& Ball, 1994) in a more recent issue of the above quoted journal as follows: "Decline in the wellbeing of carers and attenders was seen with a regression to preclosure levels. The results suggest the importance of day hospitals to the patients and their carers". Could this be the same Dr Ball who has been writing to the Bulletin? (Ball, 1993).

Perhaps Dr Philpott could use his considerable organisational abilities to determine whether we are dealing with an unusual form of Capgras syndrome with each member of a double Dr Ball arguing a different case while we try to obtain funds to carry out a systematic and comparative study of various forms of care in old age psychiatry.

The citation of Bergmann et al (1978) to cast doubts on psychogeriatric day care is not apposite. The paper only dealt with demented patients and the only outcome measures were survival in the community and mortality. An appropriate enquiry should include functional psychogeriatric disorders and employ a wider range of criteria.

While we have never disagreed with the need for better health service evaluation of day hospitals, community teams, in-patient units and 
other forms of intervention, we would caution against disposing of the day hospital as a means of treatment and assessment especially in dense urban areas as it may present the only opportunity available to carry out detailed multidisciplinary assessments on people before they are relegated to the mercy of 'community care'.

BALL, C.J. (1993) Day care in old age psychiatry. Psychiatric Bulletin, 17, 427-428.

BeATS, B., TRINKLE, D. \& LEVY, R. (1993). Day Hospital provision for the elderly mentally ill within the South East Thames Regional Health Authority. International Journal of Gerlatric Psychiatry. 8, 5, 442-443.

Rolleston. M. \& BALL. C. (1994). Evaluating the effects of brief day hospital closure. International Journal of Geriatric Psychiatry. 9, 51-53.

RAYMOND LEVY and KLAUS BERGMANN, Institute of Psychiatry and Maudsley Hospital, London SE5 8AZ

Sir: I welcome Dr Philpott's contribution to the debate which recognises the validity of the question being asked and the value of taking lessons from the experience of geriatric medicine. Unfortunately, limitations of space led me to curtail this line of enquiry in the original paper. He is right to assert that others may begin to take an increasingly important role in deciding service provision if these questions are not raised.

The main thrust of the discussion in our paper (Rolleston \& Ball, 1994), to which Bergmann \& Levy (this journal) refer, relates to this very issue. The discussion highlights the importance of monitoring decisions regarding services not taken on clinical grounds. The study also says nothing about the relative merits of one form of service delivery over another; only that people miss a service once it has been withdrawn, which comes as no surprise. As some staff from the day hospital were deployed elsewhere in the hospital during this period, perhaps using their skills to support people in their own homes could have reduced the effect we demonstrated.

The local issues which make one form of service delivery more applicable in one area than another may well be paramount. The example of Professor Wilkinson (1994) who has attempted a number of ways of working in the community before settling on a particular model, is a lesson to us all in finding the best way to deliver services to a given population. The answer is unlikely to be the same in all circumstances.

In their initial reply to Ball (1993), Bergmann \& Levy (1994) gave a brief resumé of the types of patients that they had cared for in the day hospital setting, which did not include those suffering from dementia - perhaps because they feel that the citing of their work on dementia and the day hospital is not apposite to the argument. I find this surprising, as such a large percentage of the work done by an old age psychiatry team is with this patient group and their carers. Were none of the 2449 day attendances offered to those with a dementing illness? I agree that it is important to identify the patient groups for whom the day hospital or other service are likely to be most effective, but such a large group of users cannot be summarily dismissed from the debate.

It is the nature of research that results are obtained that do not entirely fit our expectations. These should be used to simulate further discussion and questioning, not to dismiss the researcher as a psychopathological phenomena of dubious diagnostic significance.

BALL. C.J. (1993) The future of day care in old age psychiatry. Psychiatric Bulletin, 17, 427-428.

BERGMANN. K.L. \& LEVY, R. (1994) Day care in old age psychiatry. Psychiatric Bulletin, 18, 53-54.

Rolleston, M. \& BALL, C.J. (1994) Evaluating the effects of brief day hospital closure. International Journal of Geriatric Psychiatry, 9, 51-53.

WILKINSON. D.G. (1994) Day hospitals by any other name. International Journal of Geriatric Psychiatry, 9, 161.

CHRISTOPHER J. BALL, The London Hospital Medical College, Turner Street, London E1 2AD

\section{Social psychiatry}

Sir: I was surprised and dismayed to hear that the College is thinking of changing or dividing the functions and name of the Section of Social, Community and Rehabilitation Psychiatry. This seems unfortunate since social psychiatry is the theoretical base which underpins both rehabilitation and community psychiatry. In rehabilitation, for some reason treatment has often failed and relatively little can be done to alter the person's disabilities. Then the only satisfactory approach in physical rehabilitation is to modify the environment by the provision of ramps, lifts, crutches, guide dogs, wheelchairs and other devices. In psychiatric rehabilitation, changes in the social environment are needed, but this is a much more complicated operation which will become even more difficult as rehabilitation moves out of the mental hospital into the 'community'. It will involve multidisciplinary action in which the psychiatrist has a significantly different, but no less skilful, part to play (informed by an understanding of social psychiatric research findings) if he or she is going to maintain any position of leadership which, I believe, is one of the College's aims.

There is even more at stake; over $\mathbf{4 0}$ years ago Sir Aubrey Lewis wrote that the study of mental illness must be incomplete if social factors were not taken into account and so he founded the MRC Social Psychiatry Unit in the Institute of Psychiatry. Its work and that of the College has still a long way to go: thus the College Section, 